\title{
Health seeking and sexual behaviour of men presenting with sexually transmitted infections in two primary health care clinics in Durban
}

\author{
M Nyalela*, T Dlungwane, M Taylor and N Nkwanyana \\ School of Nursing and Public Health, College of Health Sciences, University of KwaZulu-Natal, Durban, South Africa \\ *Corresponding author, email: nyalelam@yahoo.co.uk; nyalelam@ukzn.ac.za
}

Check for updates

Background: Sexually transmitted infections (STIs) remain a major public health problem globally, with men being the main transmitters of infections. A high prevalence of curable STIs is reported in adults aged between 15 and 49 years, and the delay in seeking treatment has adverse consequences for both the individual and population.

Objective: A study was undertaken to assess the factors associated with the health seeking and sexual behaviour of men presenting with STIs at the two primary health care sites in eThekwini metropolitan area.

Method: A cross-sectional study design with systematic random sampling was used. Data were collected using an intervieweradministered questionnaire and analysed using STATA.

Results: Some $23 \%$ of the 134 participants delayed coming to the clinic after noticing the signs and symptoms of an STI. Participants were 5.89 (95\% Cl 1.49-23.32) times more likely to delay seeking treatment if they sought medical help only when perceiving an illness to be severe, and three times more likely to delay (borderline result) if they only used a condom when sober (OR 3.16; $95 \% \mathrm{Cl}$ 0.99-10.06). Staff stigma and the bad attitude of nurses were factors that delayed men visiting the clinic for STI treatment and this was reported by $76(56.7 \%)$ of the participants.

Conclusion: Delayed health seeking behaviour amongst men with STIs remains a major challenge. Appropriate interventions are required to deal with factors associated with delayed health seeking behaviour amongst men with STIs.

Keywords: clinics, delayed, health seeking behaviour, men, sexually transmitted infections

\section{Introduction}

Sexually transmitted infections (STIs) are among the most common acute conditions worldwide. ${ }^{1-5}$ The 2012 WHO report estimated nearly 500 million incident cases of STIs per year in adults aged between 15 and 49 years in the world. ${ }^{5}$ More than one million people in the world become infected with STIs every day. ${ }^{5,6}$ In the African context, the overall yearly incidence rate of curable STIs is estimated at 254 per 1000 people in the reproductive ages 15-49 years, while only 77-91 per 1000 in developed countries. ${ }^{7}$

Men are generally less likely to seek medical help or utilise available health services when experiencing health problems. ${ }^{1,8,9}$ The various reasons associated with delayed health seeking behaviour include limited access to health services, health workers' attitudes (female nurses' rudeness, prejudice and judgemental attitudes), as well as sociocultural, economic and gender issues. $^{1,2,10}$

Despite the wide range of reasons for the delay in health seeking behaviour, there are consequences that are endured by those who delay seeking treatment when experiencing STI signs and symptoms. ${ }^{10}$ The long duration of infection, and untreated ulcerative or non-ulcerative infection can increase the chances of HIV infection transmission by up to 10 times and more, cause severe illness and increase mortality and infertility. ${ }^{3}$ Controlling STIs is critical in preventing HIV. The control of STIs is a priority in South Africa. The National Strategic Plan (NSP) on HIV, STIs and tuberculosis (TB) (2012-2016) recommended a comprehensive approach in addressing the social and structural barriers that increase vulnerability to STIs. ${ }^{11}$
KwaZulu-Natal (KZN) province reported an annual STI incidence rate of $6.3 \% .{ }^{12}$ The high burden of STIs in the two primary health care facilities in this study is reflected in the number of patients presenting with STIs. On average, 7100 patients with STIs are treated in each health facility annually. Despite the high burden of STIs in these health facilities, little is known about the health seeking behaviour of men presenting with STIs. Men often play a dominant role in decision-making in a relationship between partners when it comes to sexual practices. ${ }^{13}$ The aim of the study was to assess the factors associated with the health seeking and sexual behaviour of men presenting with STIs at the two primary health care sites in eThekwini.

\section{Methods}

\section{Design}

An observational, analytical cross-sectional study design was used. The study was undertaken in eThekwini metro, KZN, which has a population of 3.5 million. ${ }^{12}$ Men who presented with STIs at the two primary health care sites were recruited. Both health facilities, in the north and south of the city, cater for patients referred from local clinics and self-referrals. The study was conducted from March 2015 to June 2015. A systematic random sampling approach was used. Participants were screened by nurses and, once identified with an STI, every third participant was referred to research assistants to complete a questionnaire. 'People with STIs' in this study referred to patients who presented with urethral discharges, penile ulcers, perineal ulcers, genital or perineal warts or painful micturition. In this study, delayed health seeking behaviour was defined as presentation to a clinic six days after noticing STI signs and 
symptoms. The sample size of 130 was calculated assuming an STI incidence rate of $6.3 \%$ (based on KZN estimate), $5 \%$ precision level and $80 \%$ statistical power. This study sample was used to determine factors associated with health seeking behaviour for STIs.

A standardised interviewer-administered questionnaire consisting of close-ended questions was used. The questionnaires were translated into isiZulu and translated back into English to ensure reliability. Variables measured in the questionnaire included demographic information, factors associated with health seeking behaviour, knowledge about STIs, beliefs and attitudes towards seeking treatment, health system factors, and men's sexual behaviour. The questionnaire was adopted from previous quantitative studies that had investigated the health seeking behaviour of men presenting with STIs. ${ }^{1,3,10,14-16}$

\section{Data analysis}

The data were coded and entered in a Microsoft Excel spreadsheet (Microsoft Corp, Redmond, WA, USA), and exported into Stata version 13 (StataCorp, College Station, TX, USA) statistical software for analysis. Descriptive statistics, in the form of frequencies (counts) and percentages, were computed. Pearson's chi-square and Fisher's exact tests were used to test for association between categorical variables. Multiple logistic regression was used to examine factors associated with delayed health seeking behaviour. A $p$-value $<0.05$ was statistically significant. The variables that were shown to be significant $(p<0.1)$ in the bivariate analysis were included in the multivariable model.

\section{Ethical issues}

The researcher obtained permission to conduct the study from the Department of Health. The Biomedical Research Ethics Committee (BREC) granted ethics approval (BREC REF: 442/14). Each study participant received an information sheet and provided written informed consent. For the participants who could not read and write, of whom there were eight, verbal informed consent was obtained.

\section{Results}

In this study, 31 (23.1\%) of the 134 participants delayed coming to the clinic after noticing the signs and symptoms of an STI, whilst 103 (76.9\%) presented early. In total, 134 participants were included in the analysis, with 65 participants from the north of eThekwini metropolitan and 69 participants from the south of eThekwini metropolitan. The majority of the participants were single $(105 ; 78.4 \%)$, living in a township (95; $70.9 \%$ ), and had not completed secondary education (96; $71.6 \%$ ). Some $41 \%$ were aged between 26 and 35 years, and a third of participants $(48 ; 35.8 \%)$ were in full-time employment (Table 1).

There was a significant association between participants who used a condom only when sober and the delayed health seeking behaviour $(p<0.05)$. The majority of the participants $97(72.4 \%)$ did not always use a condom when they were not sober, but most presented timeously, although of the noncondom users $27(87.1 \%)$ presented late at the clinic. Although the majority of the participants $(117 ; 87.3 \%)$ did not use condoms all the time, the proportions of early versus late

Table 1: Sociodemographic profile of participants showing the proportions in the early presentation $(n=103 ; 76.9 \%)$ vs. late presentation $(n=31 ; 23.1 \%)$ groups (number, \%)

\begin{tabular}{|c|c|c|c|c|}
\hline Demographic profile & Early presentation, no. (\%) & Late presentation, no. (\%) & Total no. (\%) & $p$-value \\
\hline \multicolumn{5}{|l|}{ Age (years): } \\
\hline $18-25$ & $35(33.9)$ & $9(29.0)$ & $44(32.8)$ & 0.219 \\
\hline $26-35$ & $43(41.8)$ & $12(38.7)$ & $55(41.0)$ & \\
\hline $36-45$ & $20(19.4)$ & $5(16.1)$ & 25 (18.7) & \\
\hline $46-49$ & $5(4.8)$ & $5(16.1)$ & $10(7.5)$ & \\
\hline \multicolumn{5}{|l|}{ Place of residence: } \\
\hline Urban/city/suburban & $2(1.9)$ & $1(3.2)$ & $3(2.2)$ & 0.139 \\
\hline Township & $78(75.7)$ & $17(54.8)$ & 95 (70.9) & \\
\hline Rural & $4(3.9)$ & $2(6.5)$ & $6(4.5)$ & \\
\hline Informal settlement & $17(16.5)$ & $10(32.3)$ & $27(20.2)$ & \\
\hline Peri-urban & $2(1.9)$ & $1(3.2)$ & $3(2.2)$ & \\
\hline \multicolumn{5}{|c|}{ Educational level (not completed): } \\
\hline Primary school & $6(5.8)$ & $0(0.0)$ & $6(4.5)$ & 0.072 \\
\hline Secondary school & $68(66.0)$ & $28(90.3)$ & $96(71.6)$ & \\
\hline Tertiary level/college & $26(25.2)$ & $3(9.7)$ & $29(21.6)$ & \\
\hline No education & $3(2.9)$ & $0(0.0)$ & $3(2.2)$ & \\
\hline \multicolumn{5}{|l|}{ Marital status: } \\
\hline Single & $84(81.6)$ & $21(67.7)$ & $105(78.4)$ & 0.168 \\
\hline Married/cohabiting & $18(17.5)$ & $9(29.0)$ & $27(20.2)$ & \\
\hline Widowed & $1(0.9)$ & $1(3.2)$ & $2(1.5)$ & \\
\hline \multicolumn{5}{|l|}{ Employment status: } \\
\hline Full-time work & $37(35.9)$ & $11(35.5)$ & $48(35.8)$ & 0.312 \\
\hline Part-time work & $33(32.0)$ & $10(32.3)$ & $43(32.1)$ & \\
\hline Not employed & $19(18.5)$ & $9(29.0)$ & $28(20.9)$ & \\
\hline Student & $14(13.6)$ & $1(3.2)$ & $15(11.2)$ & \\
\hline
\end{tabular}


presentation were shown to be evenly distributed (90; $87.4 \%$ vs. $27 ; 87.1 \%)$. Similarly, an even distribution was noted among participants who used condoms only when they do not trust their partners $(86 ; 83.5 \%$ vs. $28 ; 90.3 \%)$; were not faithful to one partner $(75 ; 72.8 \%$ vs. $26 ; 83.9 \%)$; only use condoms when available $(75 ; 72.8 \%$ vs. $26 ; 87.1 \%)$; those who do not use a condom when experiencing erectile dysfunction ( $56 ; 54.4 \%$ vs. $17 ; 54.8 \%)$; and those who used a condom when they have signs of infection $(80 ; 77.7 \%$ vs. $25 ; 80.6 \%)$. Most men $(90 ; 67.2 \%)$ reported multiple sexual partners (Table 2).

Although staff stigma and bad attitude of nurses were borderline significantly associated with delayed health seeking behaviour $(p=0.096)$ regarding the proportions of early versus late presentation, the majority of the participants $63(82.9 \%)$ presented early at the clinic. The time that participants waited before coming to the clinic was significantly associated with delayed health seeking behaviour $(p<0.005)$, although the majority $(103 ; 76.9 \%)$ presented early at the clinic. The majority of the participants $(84 ; 62.7)$ felt that government is doing enough to cater for men's problems (Table 3).

Table 4 shows the unadjusted and adjusted odds ratio for factors associated with delayed health seeking behaviour. Participants who sought medical help for an STI when having a severe illness were significantly associated with delay in the final adjusted analysis, in that the participants were $4.25(95 \% \mathrm{Cl}$ 2.05-8.23) times more likely to delay seeking treatment if they sought medical help only when having an illness that they perceived to be severe. Furthermore, the odds of men delaying visiting the clinic increased by $4.21(95 \% \mathrm{Cl} 1.51-11.70)$ if they were HIV-negative $(p<0.05)$. Participants' educational level was significantly associated $(P=0.04)$ and their reasons for not coming to the clinic were borderline significant $p=0.057$.

\section{Discussion}

This study sought to assess the factors associated with the health seeking and sexual behaviour of men presenting with STIs at the two primary health care sites.

In this study $41 \%$ of the participants were between 26 and 35 years of age, suggesting that young adults are faced with the risk of acquiring STls. This was also noted in a study from Singapore, where the age group of participants showed that the majority (46\%) fell between 26 and 35 years of age. ${ }^{14}$ The risk of HIV infection is high among this age group, given that $83 \%$ of HIV-infected persons in South Africa are younger than 35 years of age. ${ }^{3}$ The findings of this study indicate the need for the educational awareness programme planners to target men below 35 years of age in particular. Furthermore, this study found that the majority $(78.4 \%)$ of the men were single and were mostly not using condoms consistently. Therefore, health educational programmes especially need to target single men.

Among the participants, $35.8 \%$ had full-time employment, whilst $32.1 \%$ had part-time employment. These findings thus show

Table 2: Men's self-reported sexual behaviour showing the proportions in the early presentation $(n=103 ; 76.9 \%)$ vs. late presentation $(n=31 ; 23.1 \%)$ groups (number, \%)

\begin{tabular}{|c|c|c|c|c|}
\hline Sexual behaviour & Early presentation, no. (\%) & Late presentation, no. (\%) & Total no. (\%) & $p$-value \\
\hline \multicolumn{5}{|c|}{ Do you use a condom all the time? } \\
\hline Yes & $13(12.6)$ & $4(12.9)$ & $17(12.7)$ & 0.589 \\
\hline No & $90(87.4)$ & $27(87.1)$ & $117(87.3)$ & \\
\hline \multicolumn{5}{|c|}{ Did you use a condom last time you had sex? } \\
\hline Yes & $31(30.1)$ & $11(35.5)$ & $42(31.3)$ & 0.571 \\
\hline No & $72(69.9)$ & $20(64.5)$ & $92(68.7)$ & \\
\hline \multicolumn{5}{|c|}{ Only use a condom when don't trust partner? } \\
\hline Yes & $86(83.5)$ & $28(90.3)$ & $114(85.1)$ & 0.565 \\
\hline No & $17(16.5)$ & $3(9.7)$ & $20(14.9)$ & \\
\hline \multicolumn{5}{|c|}{ Faithful to the partner? } \\
\hline Yes & $28(27.2)$ & $5(16.1)$ & $33(24.6)$ & 0.210 \\
\hline No & $75(72.8)$ & $26(83.9)$ & $101(75.4)$ & \\
\hline \multicolumn{5}{|c|}{ Only use a condom when available? } \\
\hline Yes & $75(72.8)$ & $27(87.1)$ & $102(76.1)$ & 0.102 \\
\hline No & $28(27.2)$ & $4(12.9)$ & $32(23.9)$ & \\
\hline \multicolumn{5}{|c|}{ Only use a condom when sober? } \\
\hline Yes & $70(67.9)$ & $27(87.1)$ & $97(72.4)$ & 0.037 \\
\hline No & $33(32.0)$ & $4(12.9)$ & $37(27.6)$ & \\
\hline \multicolumn{5}{|c|}{ Only use a condom when have signs of infection? } \\
\hline Yes & $80(77.7)$ & $25(80.65)$ & $105(78.4)$ & 0.724 \\
\hline No & $23(22.3)$ & $6(19.35)$ & $29(21.6)$ & \\
\hline \multicolumn{5}{|c|}{ Do not use a condom when experiencing erectile dysfunction? } \\
\hline Yes & $56(54.4)$ & $17(54.8)$ & $73(54.5)$ & 0.963 \\
\hline No & $47(45.6)$ & $14(45.2)$ & $61(45.5)$ & \\
\hline \multicolumn{5}{|c|}{ How many partners have you had? } \\
\hline $1-10$ & $38(36.9)$ & $6(19.4)$ & $44(32.8)$ & 0.143 \\
\hline $11-20+$ & $65(63.1)$ & $25(80.6)$ & $90(67.2)$ & \\
\hline
\end{tabular}


Table 3: Health system factors associated with men's delayed health seeking behaviour, showing the proportions in the early presentation ( $n=103$; $76.9 \%)$ vs. late presentation ( $n=31 ; 23.1 \%)$ groups (number, \%)

\begin{tabular}{|c|c|c|c|c|}
\hline Health system factors & Early presentation, no. (\%) & Late presentation, no. (\%) & Total no. (\%) & $p$-value \\
\hline \multicolumn{5}{|c|}{ Reasons for not coming to the clinic: } \\
\hline Fear staff stigma and attitude & $63(82.9)$ & $13(17.1)$ & $76(56.7)$ & 0.096 \\
\hline Don't get time off work & $19(67.9)$ & $9(32.1)$ & $28(20.9)$ & \\
\hline Prefer going to the traditional & $1(33.3)$ & $2(66.7)$ & $3(2.2)$ & \\
\hline \multicolumn{5}{|l|}{ healer } \\
\hline Don't believe clinic can help & $1(50)$ & $1(50)$ & $2(1.5)$ & \\
\hline Nothing & $19(76.0)$ & $6(24)$ & $25(18.7)$ & \\
\hline \multicolumn{5}{|c|}{ Is government doing enough to cater for men's problems? } \\
\hline Yes & $66(78.6)$ & $18(21.4)$ & $84(62.7)$ & 0.739 \\
\hline No & $17(77.3)$ & $5(22.7)$ & $22(16.4)$ & \\
\hline Don't know & $20(71.4)$ & $8(28.6)$ & $28(20.9)$ & \\
\hline \multicolumn{5}{|c|}{ Where do you go first when experiencing STI signs and symptoms? } \\
\hline Clinic & $96(80.0)$ & $24(20.0)$ & $120(89.6)$ & 0.021 \\
\hline Doctor & $2(33.3)$ & $4(66.7)$ & $6(4.5)$ & \\
\hline Traditional healer & $5(62.5)$ & $3(37.5)$ & $8(5.9)$ & \\
\hline \multicolumn{5}{|c|}{ Do you know different types of STIs? } \\
\hline Yes & $79(74.5)$ & $27(25.5)$ & $106(79.1)$ & 0.212 \\
\hline No & $24(85.7)$ & $4(14.3)$ & $28(20.9)$ & \\
\hline
\end{tabular}

that the majority of the participants were employed, and this suggests an alternative reason for their delaying presentation to the clinics, as a fifth of the participants reported that they did not get time off work. This was also reported in Singapore, where $32.4 \%$ delayed seeking treatment because they did not get time off work. ${ }^{14}$ There is therefore a need to open clinics at night to provide services for such men.

In this study, only $2.2 \%$ had no education and there were $4.5 \%$ who had not completed primary education. This suggests that most of the participants' education was above primary level, and that they were possibly literate enough to understand health education and awareness campaigns in the media. ${ }^{2}$ There is a high incidence (6.5\%) of STIs in eThekwini district (KwaZulu-Natal). ${ }^{12}$ Health policy-makers and programme planners, however, also need to address other skills, for example, engaging in prevention behaviour such as effective communication with one's sexual partner, refusal to engage in unsafe sex, and proper and consistent use of condoms. ${ }^{2}$

In this study, $23.1 \%$ of men were classified as reporting delayed health seeking behaviour, defined as presentation to a clinic more than six days after noticing the STI signs and symptoms. The delay in presentation to a clinic has been reported in other studies, although there was a difference in time intervals. $^{1-3,10,17}$ In a study done in Ghana, $64 \%$ of the patients delayed for more than four weeks before seeking treatment for a possible STI. In order to reduce the transmission, it is therefore important to understand the health seeking behaviour of men with STIs so that it will be easier to identify why and where men go for treatment, other than to the medical health care services. Understanding the reasons for the delay in seeking health care among men with STIs can assist in developing health education initiatives and public health programmes to control STIs and, in turn, HIV. ${ }^{2,10}$

There are various reasons for the delay in seeking treatment among men in our study. Among such reasons that were found to be significantly associated with delayed health seeking behaviour was severity of symptoms $(p<0.05)$. Participants who reported seeking medical help when they have a severe illness were 4.25 times more likely to delay seeking medical help compared with participants with a mild illness. A study done in Uganda also concluded that the severity and nature of the symptoms may influence a person's decision to delay his health care seeking behaviour, since clients who had genital discharge sought care late as compared with clients who had sores over their genitalia. ${ }^{2}$ This may suggest that participants delayed seeking treatment in the hope that the symptoms will go away.

The majority (87.3\%) of the participants did not use condoms all the time although $79 \%$ reported that they knew different types of STIs. Nevertheless, there was even distribution in the early versus late presentation proportions. The study done in Ghana also reported that the level of knowledge of knowledge about STIs among clients was good at $77.8 \%$, but participants did not use condoms all the time. In this study, $72.4 \%$ of the participants used condoms only if they are sober, meaning that when they are drunk they forget about using the condom. This kind of behaviour is worrying since people with greater alcohol use indicated high condom failure, thereby increasing their chances of contracting HIV and other STIs. ${ }^{18}$

Among the men, $85.1 \%$ only used condoms if they do not trust a partner, meaning once the trust is established, in a long-term relationship, they stop using condoms. The majority of participants $(76.1 \%)$ used condoms only if they were available and $78.4 \%$ use condoms only when they suspect signs of infection. This is concerning, since HIV and STIs are spread through high-risk behaviour such as low condom use. ${ }^{2} \mathrm{~A}$ number of participants in this study were at risk of exposure to STIs, and could have contracted HIV through this low condom use. This also calls for intensifying STI awareness among men, in general public areas such as taxi ranks, and in workplaces. Such campaigns must emphasise the dangers of having unprotected sex. 
Table 4: Unadjusted and adjusted odds ratio $(95 \% \mathrm{Cl})$ of factors associated with delayed health seeking behaviour $(n=134)$

\begin{tabular}{|c|c|c|c|}
\hline Variables & $\begin{array}{l}\text { Odds } \\
\text { ratio }\end{array}$ & $95 \% \mathrm{Cl}$ & $\begin{array}{c}p \text { - } \\
\text { value }\end{array}$ \\
\hline \multicolumn{4}{|l|}{ Unadjusted odds ratio: } \\
\hline $\begin{array}{l}\text { Participants saw a traditional } \\
\text { healer more than seven times a } \\
\text { year }\end{array}$ & 2.29 & $0.37-14.42$ & 0.374 \\
\hline $\begin{array}{l}\text { Participants felt that government } \\
\text { is not doing enough to cater for } \\
\text { men's health problems }\end{array}$ & 0.78 & $0.34-1.77$ & 0.544 \\
\hline $\begin{array}{l}\text { Participants seek medical help } \\
\text { for an STI when having severe } \\
\text { illness }\end{array}$ & 5.94 & $1.56-22.66$ & 0.009 \\
\hline $\begin{array}{l}\text { Participants who did not know } \\
\text { their HIV status }\end{array}$ & 0.34 & $0.15-0.77$ & 0.010 \\
\hline $\begin{array}{l}\text { Participants who were HIV- } \\
\text { negative }\end{array}$ & 0.33 & $0.14-0.79$ & 0.012 \\
\hline $\begin{array}{l}\text { Participants who use a condom } \\
\text { only when sober }\end{array}$ & 3.18 & $1.03-9.84$ & 0.044 \\
\hline Educational level & 0.34 & $0.13-0.92$ & 0.034 \\
\hline $\begin{array}{l}\text { Where participants go first when } \\
\text { experiencing STI signs and } \\
\text { symptoms }\end{array}$ & 1.45 & $0.64-3.28$ & 0.372 \\
\hline $\begin{array}{l}\text { Reasons for not coming to the } \\
\text { clinic }\end{array}$ & 1.54 & $0.99-2.39$ & 0.052 \\
\hline \multicolumn{4}{|l|}{ Adjusted odds ratio: } \\
\hline $\begin{array}{l}\text { Participants seek medical help } \\
\text { for an STI when having severe } \\
\text { illness }\end{array}$ & 4.25 & $2.05-8.23$ & 0.000 \\
\hline $\begin{array}{l}\text { Participants who use a condom } \\
\text { only when sober }\end{array}$ & 0.29 & $0.08-1.17$ & 0.082 \\
\hline $\begin{array}{l}\text { Participants who were HIV- } \\
\text { negative }\end{array}$ & 4.21 & $1.51-11.70$ & 0.006 \\
\hline Educational level & 0.36 & $0.14-0.95$ & 0.040 \\
\hline $\begin{array}{l}\text { Reasons for not coming to the } \\
\text { clinic }\end{array}$ & 1.52 & $0.99-2.33$ & 0.057 \\
\hline
\end{tabular}

Level of significance $p<0.05$.

Variables included in the multivariate analysis were statistically significant and marginally significant, $p<0.1$.

Variables controlled for in the final adjusted analysis were: Participants seek medical help for an STI when having severe illness; Participants who use a condom only when sober; Participants who were HIV negative; Educational level; and Reasons for not coming to the clinic.

Although the majority of participants (89.6\%) reported going first to the clinic when experiencing STI signs and symptoms, traditional healers played a role in some men's health seeking behaviour. In total, $6 \%$ of the participants reported that they initially went to see traditional healers when they noticed signs and symptoms of STIs, before coming to the clinic. Furthermore, participants who visited traditional healers more than seven times a year were 2.29 times more likely to delay seeking medical help compared with participants visiting less frequently, although this was not statistically significant. This suggests the need for health education and awareness concerning the importance of going to the clinic early. In a study done in Gauteng, some men also delayed seeking treatment from clinics because they preferred to go to traditional healers, since they believe that traditional medicine removes the root cause of an STI, and offers expedited treatment and more privacy than public clinics. This belief resulted in delayed treatment seeking from the clinics among men, whilst they were still attending traditional healers. $^{18}$

\section{Limitations}

The study findings are possibly limited by the fact that only those who experienced STI symptoms and sought care at the clinics were included. Those who did not seek care may have different characteristics and this could limit the generalisation of the study findings. Since both sexual activities and condom usage were self-reported while participants were symptomatic, this may have led to recall bias and socially desirable answers due to embarrassment. Furthermore, the structured questions did not allow an in-depth narration of the participants' experiences, and the reasons for the severe delay in health seeking behaviour could have also been further explored if a qualitative in-depth study had been done. It was also a cross-sectional study and this design limits the interpretation of the direction of the association.

\section{Conclusion}

The health workers' unpleasant attitudes, however, remain an obstacle to men accessing health care services. Men sought medical help when signs and symptoms were perceived to be severe. It is worrying, however, that the majority of men still engage in risky sexual behaviour that may increase the chances of becoming infected with STIs, including HIV. Furthermore, most of the participants reported using a condom only when they were sober. There is, therefore, a need to deal with men's attitudes towards their sexual health. However, the possibility remains of underutilisation of the information or lack of implementation of policies derived from the research findings, but this study hopes to contribute towards the development of effective programmes that can reduce STIs and HIV infections. Further studies may also need to investigate sexual activities among men who have sex with both men and women, as well as with men exclusively, within and outside KZN.

Disclosure statement - No potential conflict of interest was reported by the authors.

\section{References}

1. Langeni T. Contextual factors associated with treatment-seeking and higher-risk sexual behaviour in Botswana among men with symptoms of sexually transmitted infections. Afr J AIDS Res. 2007;6 (3):261-9. https://doi.org/10.2989/16085900709490422

2. Agambire $\mathrm{R}$, Clerk $\mathrm{C}$. Healthcare seeking and sexual behaviour of clients attending the suntreso STI clinic. J Biol Agric Healthc. 2013;3 (10):92-100. [cited 2014 Aug 14]. Available from: www.iiste.org/ Journals/index.php/JBAH/article/viewFile/7242/7265

3. Meyer-Weitz A, Reddy P, Van den Borne HW, et al. Health care seeking behaviour of patients with sexually transmitted diseases: determinants of delay behaviour. Patient Educ Couns. 2000;41 (3):263-74. https://doi.org/10.1016/s0738-3991(99)00103-2

4. Johnson L, Bradshaw D, Dorrington R. The burden of disease attributable to sexually transmitted infections in South Africa in 2000. S Afr Med J. 2007;97(8):658-62. [cited 2015 Sep 15]. Available from: samj.org.za/index.php/samj/article/view/657/0

5. World Health Organization. Global incidence and prevalence of selected curable sexually transmitted infections-2008. Geneva, Switzerland: WHO; 2012. [cited 2014 Jun 8]. Available from: http:// www.who.int/iris/bitstream/10665/75181/1/9789241503839_eng. pdf

6. Newman L, Rowley J, Vander Hoorn S, et al. Global estimates of the prevalence and incidence of four curable sexually transmitted infections in 2012 based on systematic review and global reporting. PLoS One. 2015;10(12). [cited 2018 Jun 20]. Available from: https://doi.org/ 10.1371/journal.pone.0143304.t001

7. Mayaud $\mathrm{P}, \mathrm{McC}$ Cormick $\mathrm{D}$. Interventions against sexually transmitted infections (STI) to prevent HIV infection. Br Med Bull. 2001;58 (1):129-53. https://doi.org/10.1093/bmb/58.1.129 
8. Galdas PM, Cheater F, Marshall P. Men and health help-seeking behaviour: literature review. J Adv Nurs. 2005;49(6):616-23. https:// doi.org/10.1111/j.1365-2648.2004.03331.x

9. McVittie C, McKinlay A. Help-seeking in context: masculine and feminine identities in relation to men's health issues. Procedia Soc Behav Sci. 2010;5:239-43. https://doi.org/10.1016/j.sbspro.2010.07.080

10. Govender I, Eche M. Health-seeking behaviour of people with sexually transmitted infections in the community of Nkomazi East, Mpumalanga. South Afr J Epidemiol Infect. 2012;27(4):195-8. [cited 2014 Aug 15]. Available from: www.sajei.co.za > Home > Vol 27, No 4 (2012) > Govender

11. National Department of Health, South Africa. National strategic plan on HIV, STIs and TB: 2012-2016. Pretoria: Government Printers; 2012. [cited 2015 Sep 23]. Available from: http://www.sahivsoc.org/upload/ documents/National_Strategic_Plan_2012.pdf

12. Health Sytem Trust. The district health barometer 2010/11, section B: district and provincial profiles. Durban, South Africa; 2011. [cited 2015 Aug 2]. Available from: http://www.hst.org.za/

13. Kumar A. Role of males' in reproductive and sexual health decisions. Bihar Times SSRN Electron J. 2009. https://doi.org/10.2139/ssrn.1349894

14. Jayabaskar T. Health care seeking behaviour of patients attending an STI clinic in Singapore [Dissertation]. National University of
Singapore, Master's Theses, 2004. [cited 2015 Oct 11] Available from: http://scholarbank.nus.edu.sg

15. Choudhury, AY, Arjumand, L, Piwoo, JS. 1997. A rapid assessment of health seeking behavior in relation to sexually transmitted disease. PIACT Bangladesh. [cited 2014 Aug 3]. Available from: www.who. int/hiv/topics/HealthcareSeeking

16. Van der Hoeven M, Kruger A, Greeff M. Differences in health care seeking behaviour between rural and urban communities in South Africa. Int J Equity Health. 2012;11(1):31. [cited 2015 Feb 3]. Available from: http://www.equityhealthj.com/content/11/1/31

17. Case A, Menendez A, Ardington C. Health seeking behaviour in northern KwaZulu-Natal. Universty of Cape Town: Centre for Social Science Research 2005. [cited 2014 Mar 17]. Available from: http://hdl.handle. net/11090/665

18. Leichliter JS, Paz-Bailey G, Friedman LA, et al. 'Clinics aren't meant for men': sexual health care access and seeking behaviours among men in Gauteng province, South Africa. SAHARA J J Soc Asp HIV/AIDS. 2011;8(2):82-8. https://doi.org/10.1080/17290376. 2011.9724989 